\title{
Thenar muscle blood flow and bone mineral in the forearms of lumberjacks
}

\author{
P. KARJALAINEN, E. M. ALHAVA, and J. VALTOLA \\ Department of Surgery, University Central Hospital, Kuopio, Finland
}

\begin{abstract}
Karjalainen, P., Alhava, E. M., and Valtola, J. (1975). British Journal of Industrial Medicine, 32, 11-15. Thenar muscle blood flow and bone mineral in the forearms of lumberjacks. Forty lumberjacks who had used a chain saw for 0-20 years and who had no general disease affecting the bones were studied by measuring the thenar muscle blood flow of both hands by the ${ }^{133} \mathrm{Xe}$ local clearance method. Bone mineral in the left forearm in the region of cancellous and cortical bone was assessed by the ${ }^{241} \mathrm{Am}$ gamma ray attenuation method.

Vibration was found to decrease the blood flow in the saw-bearing left hand compared with the right hand of the lumberjacks. The bone mineral density $\left(\mathrm{g} / \mathrm{cm}^{3}\right)$ was lower in the forearm bones of the lumberjacks than in controls of the same age with healthy bones. Moreover the poorer the thenar muscle blood flow, the greater was the decrease in the mineral density of the distal radius. Measurement of the mineral density of the forearm bones by the gamma ray attenuation method can be used for early detection of bone lesions in traumatic vasospastic disease.
\end{abstract}

Raynaud's phenomenon of occupational origin has been known for many decades (Hamilton, 1918; Agate, 1949; Kylin and Lidström, 1970). This vibration disorder is also called traumatic vasospastic disease (TVD). In addition to TVD, skeletal changes in the upper limbs caused by the use of vibrating tools have been described since the 1930s (Meiss, 1933; McLaren, 1937; Vainio, 1950; Hunter, 1964; Wilson, McCormick, Tatum, and Creech, 1967; Horváth, Kákosy, and Villányi, 1969; de Larrard and Saldarkhan, 1970; Kumlin, Wiikeri, and Sumari, 1973).

In Finland, there were approximately 160000 saws in use in 1973 (Kumlin et al., 1973). Bearing in mind the size of our forest industry, the cold climate, and the increasing number of vibrating tools, we need objective methods for the early diagnosis of TVD and its complications.

The aim of this study was to measure the thenar muscle blood flow by the ${ }^{133} \mathrm{Xe}$ local clearance method (Lassen, Lindbjerg, and Munck, 1964) and the bone mineral linear density $(\mathrm{g} / \mathrm{cm})$ and density $\left(\mathrm{g} / \mathrm{cm}^{3}\right)$ by the ${ }^{241} \mathrm{Am}$ gamma ray attenuation method
(Karjalainen, 1973) in otherwise healthy lumberjacks, and to evaluate the role of these tests in the diagnosis of vibration disorders.

\section{Subjects}

The subjects were 40 lumberjacks who had used a chain saw. We chose men over 30 years of age who were healthy except for the possible effects of vibration. The mean age was $39 \pm 6$ years (mean $\pm 1 \mathrm{SD}$ ) range $30-56$ years. The average time that the men had owned a chain saw was $12 \pm 5$ years (mean \pm 1 SD) range 0-20 years. As a control group for the xenon clearance test we selected 25 healthy men ranging in age from 25 to 58 , mean 38 土 9 years (mean $\pm 1 \mathrm{SD}$ ). A group of 52 persons with healthy bones was used as the control series for the mineral measurements (Alhava and Karjalainen, 1973).

\section{Methods}

The muscle blood flow was measured from the thenar muscles of both hands using the ${ }^{133} \mathrm{Xe}$ local clearance method. The xenon solution was injected slowly with a small needle $(0.45 \times 13 \mathrm{~mm})$ at a depth of $1 \mathrm{~cm}$ into the thickest point of the thenar muscle. The amount of 
solution was $0.1 \mathrm{ml}$, corresponding to $50-100 \mu \mathrm{Ci}$ of ${ }^{133} \mathrm{Xe}$. Ten minutes was allowed after the injection for the solution to stabilize in the muscle. A $12 \mathrm{~cm}$ broad blood pressure cuff was then applied round the upper arm at a pressure of $250 \mathrm{mmHg}$ for five minutes to make the hand ischaemic. For the last two minutes of the ischaemic period the subject exercised the thenar muscles by compressing soft rubber balls with his hands. The blood pressure cuff was loosened and the xenon clearance curve was recorded using a $\mathrm{NaI}(\mathrm{T} 1)$ detector and an analyzerratemeter-recorder device. The muscle blood flow (MBF) was calculated from the equation $\mathrm{MBF}=100 \lambda_{\mathrm{xek}}$, where $\lambda_{\mathrm{Xe}}(=0.7 \mathrm{ml} / \mathrm{g})$ (Conn, 1961) is the blood partition coefficient, assuming that the skeletal muscle value is suitable for thenar muscle, and $k=\ln 2 / t \frac{1}{2} ; t \frac{1}{2}$ is the half-time of the tangent to the steepest descent of the logarithmic clearance curve.

The bone mineral was measured using a modification of the gamma ray attenuation method. The source of the radiation was a $45 \mathrm{mCi}{ }^{241} \mathrm{Am}$ radionuclide with a gamma energy of $60 \mathrm{keV}$. The forearm to be measured was fixed in a waterbath between the source and the detector. The result recorded was the mean of four scans across the measuring site of the bone. The measurement was made about $1.5 \mathrm{~cm}$ from the distal end of the left radius in the region of cancellous bone. The bone mineral density $\left(\mathrm{g} / \mathrm{cm}^{3}\right)$ was calculated from the equation

where

$$
\rho=\mathrm{K} \lambda / \mathrm{A} \text {, }
$$

$K=1+a \exp \left(-b \sum_{i=1}^{n} \ln \left(I_{o} / I_{i}\right) / A\right)$,

$\lambda=\frac{\Delta x \rho_{\mathrm{m}}}{\mu_{\mathrm{m}} \rho_{\mathrm{m}}-\mu_{\mathrm{s}} \rho_{\mathrm{s}}} \sum_{\mathrm{i}=1}^{\mathbf{n}} \ln \left(\mathrm{I}_{\mathrm{o}} / \mathbf{I}_{\mathrm{i}}\right) \quad$ or the mineral linear

density $(\mathrm{g} / \mathrm{cm})$ of the bone, and $\mathrm{A}\left(=0.47\left(\mathrm{~d}^{2}+1\right)\right.$, where $\mathrm{d}$ is the width of the distal radius $\rho$ ) is the cross-sectional area of the bone at the measuring site,

a $=5 \cdot 42$,

b $=4.95 \mathrm{~cm}^{2}$,

$I_{0}=$ the photon fluence rate that has penetrated water (soft tissue),

$I_{\mathbf{i}}=$ the photon fluence rate that has penetrated bone and water,

$\mu_{\mathrm{m}}=$ the mass attenuation coefficient for bone mineral $\left(=0.395 \mathrm{~cm}^{2} / \mathrm{g}\right)$,

$\rho_{\mathrm{m}}=$ the microscopic density of bone mineral $(=2 \cdot 70$ $\mathrm{g} / \mathrm{cm}^{3}$ )

$\mu_{\mathrm{s}}=$ the mass attenuation coefficient for water (soft tissue) $\left(=0.205 \mathrm{~cm}^{2} / \mathrm{g}\right)$,

$\rho_{\mathrm{s}}=$ the density of water (soft tissue) $\left(=1.00 \mathrm{~g} / \mathrm{cm}^{3}\right)$,

$\Delta \mathrm{x}=$ the distance of the points across the bone where the summation of $\ln \left(I_{0} / I_{i}\right)$ was made $(=0 \cdot 10 \mathrm{~cm})$ and

$\mathrm{n}=$ the number of points from which the sum was calculated.

Working on the assumption that the cross-section of the compact bones in the forearms is a circle, a mineral density index was calculated from $\rho=\lambda / \mathbf{A}$, in which
$A=\frac{\pi}{4}\left(d_{2}{ }^{2}-d_{1}{ }^{2}\right) \cdot d_{2}$ and $d_{1}$ are the outer and inner diameters of the bones measured from radiographs. Measurements of the cortical bone were made at the point between the middle and distal thirds of the radius and ulna.

The methods used and the constants required have already been presented in detail (Karjalainen, 1973; Alhava and Karjalainen, 1973). In the statistical analysis, the results of the bone mineral measurements were compared with a normal group (Alhava and Karjalainen, 1973) for which the regression line of the left hand was calculated in the age range $30-80$ years. The control values were taken from the regression line at a point corresponding to the age of the lumberjack.

\section{Results}

\section{Subjective symptoms connected with vibration}

When asked about their subjective complaints associated with the vibration of the saw, 19 out of 38 reported numbness of the fingers $(50 \%)$ and 17 out of 38 had the white finger phenomenon (45\%). Raynaud's phenomenon was statistically significantly more common $(13 / 20$ versus $4 / 18)(P<0.05)$ in the men who had used a chain saw for over 10 years than in those who had worked with it for a shorter time. The difference for finger numbness in these groups was not statistically significant, though this disturbance was more common in the former group. However, taking white finger phenomenon and numbness together, the difference $(10 / 20$ versus $2 / 18)$ was statistically significant $\left(P<0.05 ; \chi^{2}\right.$ test). The effective working time (working years $x$ working months/year) of the lumberjacks who had white finger phenomenon or numbness was statistically significantly longer than that of lumberjacks without symptoms $(\mathrm{P}<0.05, t$ test $)$.

\section{Muscle blood flow}

The mean muscle blood flow of the left hand of the lumberjacks was $(49 \pm 20) \mathrm{ml} /(100 \mathrm{~g} \mathrm{~min})$ and $(64 \pm 23) \mathrm{ml} /(100 \mathrm{~g}$ min) on the right side (mean $\pm 1 \mathrm{SD})$. The difference was statistically significant $(\mathrm{P}<0.001)$. In the control group this lateral difference was not statistically significant ( $t$ test, paired comparison).

\section{Radiographs}

We were unable to find any bone vacuoles typical of vibration disorder in posteroanterior radiographs of the forearm and carpal and metacarpal bones of the lumberjacks. Neither did we observe Kienboeck's disease.

\section{Mineral density of forearm bones}

The bone mineral linear density $(\mathrm{g} / \mathrm{cm})$ of the radial diaphysis was statistically lower in the lumberjacks than in the controls (Table), but there was no difference in this respect in the ulnar diaphysis and 


\section{TABLE}

Means and Standard Deviations of Bone Mineral Linear Density and Mineral Density of 40 LumberJacks aNd CORRESPONDING CONTROL VALUES.

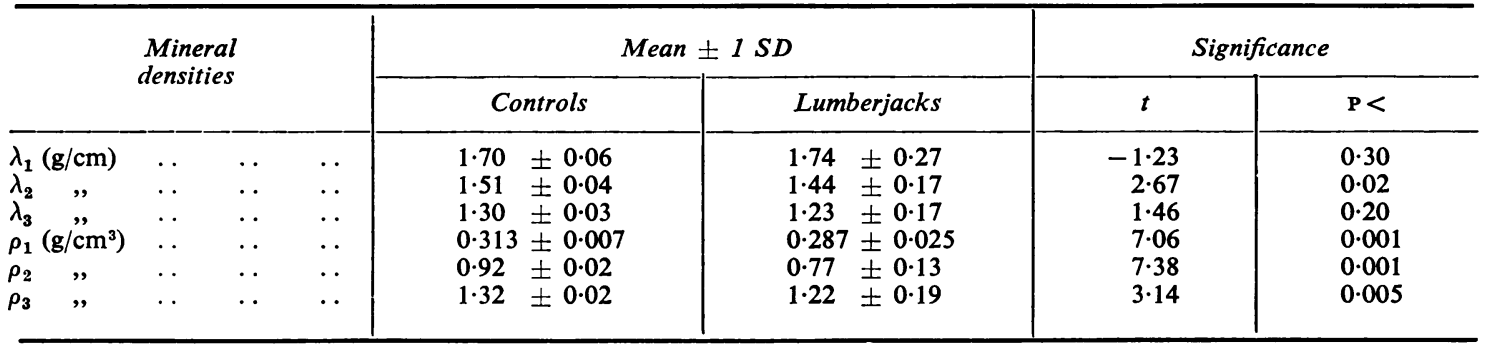

${ }^{1}$ The $t$ test and paired comparison were used for the statistical analysis. $\lambda_{1}=$ bone mineral linear density of the distal radius, $\lambda_{2}=$ bone mineral linear density at the boundary of the middle and distal thirds of the radius, and $\lambda_{3}=$ at the corresponding site on the ulna. $\rho_{1}, \rho_{2}$ and $\rho_{3}$ denote mineral density at the corresponding sites.

distal radius. However, the mineral density $\left(\mathrm{g} / \mathrm{cm}^{3}\right)$ was statistically significantly lower in the lumberjacks than in the controls at every measuring site (Table; Fig. 1). The correlation between the decrease in the mineral density of the left distal radius $(\Delta \rho=\rho$ control $-\rho$ lumberjack $)$ and the effective working time with the chain saw was statistically significant $(\mathrm{r}=0.33, \mathrm{P}<0.05)$ (Fig. 2).

The decrease in the mineral density of the distal

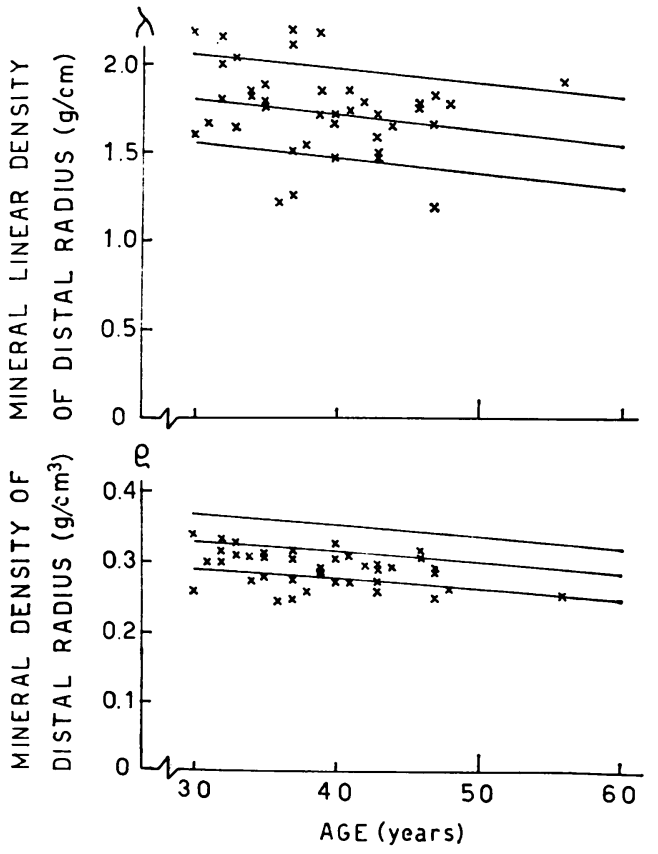

FIG. 1. Bone mineral linear density and mineral density of the distal radius in $\mathbf{4 0}$ lumberjacks. Regression line with 1 SD for the control material from the age of 30 years is plotted. radius correlated with the thenar muscle blood flow $(r=0.36 ; P<0.05)$ (Fig. 3).

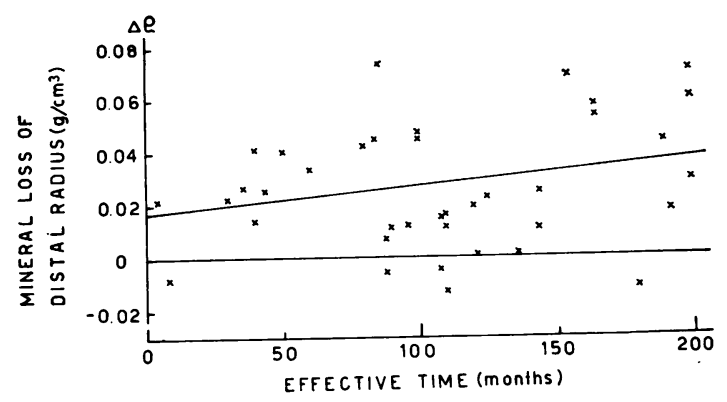

FIG. 2. Correlation between the mineral loss of the distal radius and the effective working time of 38 lumberjacks. The regression line was $\Delta \rho\left(\mathrm{g} / \mathrm{cm}^{3}\right) \quad 0.0167+$ $0.0001 \times$ time (months), $\mathrm{r}=0.33$.

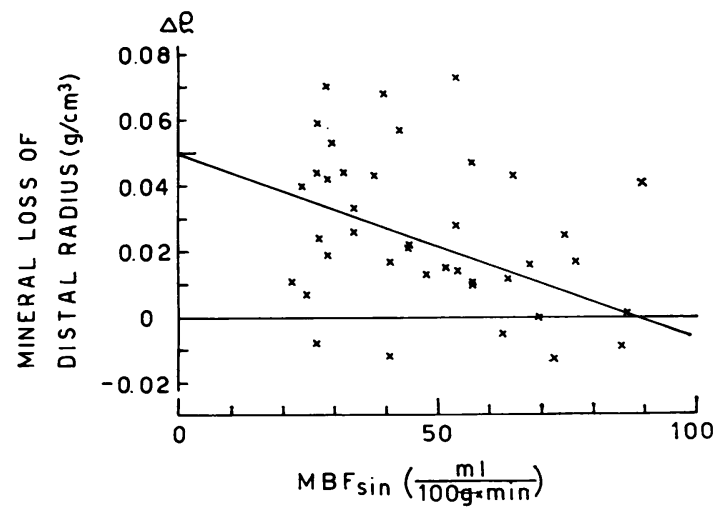

FIG. 3. Correlation between the mineral loss of the distal radius and the thenar muscle blood flow of 40 lumberjacks. The regression line was $\Delta \rho\left(\mathrm{g} / \mathrm{cm}^{3}\right)=0.0500$ $-0.0006 \times \mathrm{MBF}_{\mathrm{sin}}($ in $\mathrm{ml} /(100 \mathrm{~g} \mathrm{~min})), \mathrm{r}=0.36$. 


\section{Discussion}

It is generally accepted that vibration angiopathy, which is vasoconstrictive and even obliterative, is probably the primary cause of skeletal changes in TVD (Kumlin et al., 1973). Organic vascular abnormalities are seen only in advanced cases. Signs of vibration disorder are considered to be positive provocation tests of Raynaud's phenomenon, disturbances in the function of the joints, skeletal changes, electroneuromyographic disorders, and weakening of the sense of touch (Kumlin, 1973).

Our series comprised working lumberjacks selected on the grounds that they were over 30 years old and otherwise healthy. In this respect our material differs from that of Kumlin et al. (1973). The object of the xenon clearance test in our study was to provoke a kind of Raynaud's phenomenon, i.e., a variation of the provocation tests which are generally considered to be reliable in the diagnosis of TVD. Gamma ray attenuation methods for measuring bone mineral are considered to be the most accurate available (Shimmins et al., 1972). Goldsmith et al. (1973) reported conflicting results with these methods, but they used mineral linear density $(\mathrm{g} / \mathrm{cm})$, which is not recommended for comparisons between individual subjects (Karjalainen, 1973). Mineral density $\left(\mathrm{g} / \mathrm{cm}^{3}\right)$ is the most rational measure. It has been shown in animals (Saville and Whyte, 1969) that increased muscle activity increases the volume of bones but not the density $\left(\mathrm{g} / \mathrm{cm}^{3}\right)$. Our results, especially in the region of the distal radius, support this finding. The bone mineral linear density $(\mathrm{g} / \mathrm{cm})$ was little higher in the lumberjacks than in the controls, but the mineral density was statistically significantly lower than in the control series.

Kumlin (1970) studied the bone mineral content of lumberjacks, using the metacarpals as a measuring point, and could not find any difference from the controls. This might have been due to the inaccuracy of the method. Reports of skeletal changes have generally been based on describing various typical findings, e.g., bone cysts and Kienboeck's disease. The xenon clearance test has not been applied. We noted that the muscle blood flow was worse in the left than in the right hand of the lumberjacks. The reason was the more severe vibration in the sawbearing left hand (Kumlin et al., 1973). The mineral density $\left(\mathrm{g} / \mathrm{cm}^{3}\right)$ at every measuring site was lower than in the controls. The mean of the combined cortical thickness in the radial diaphyses of the lumberjacks was about $7 \%$ higher than that of controls of the same age. This may explain why the differences between the linear densities $(\mathrm{g} / \mathrm{cm})$ of the lumberjacks and controls were smaller than those of the mineral densities $\left(\mathrm{g} / \mathrm{cm}^{3}\right)$. It was also observed that radiographic signs of vibration disease, e.g., vacuoles, were missing. Comparing our results with those of Kumlin et al. (1973), this difference may be due to the sensitivity of the gamma ray attenuation method and to the better health of our lumberjacks. The former is supported by the finding that there was a significant correlation between the mineral loss of the distal radius and the effective working time. The correlation between the muscle blood flow and the mineral loss supports the idea that the cause of both is vibration. In conclusion, it can be stated that measurement of the mineral density of the distal radius is a feasible test for early detection of bone lesions in TVD.

\section{References}

Agate, J. N. (1949). An outbreak of cases of Raynaud's phenomenon of occupational origin. British Journal of Industrial Medicine, 6, 144-163.

Alhava, E. M. and Karjalainen, P. (1973). The mineral content and mineral density of bone of the forearms in healthy persons measured by Am-241 gamma ray attenuation method. Annals of Clinical Research, 5, 238-243.

Conn, H. (1961). Equilibrium distribution of radioxenon in tissue. Journal of Applied Physiology, 16, 1065.

Goldsmith, N. F., Johnston, J. O., Picetti, G., and Garcia, C. (1973). Bone mineral in the radius and vertebral osteoporosis in an insured population. A correlative study using ${ }^{125}$ I photon absorption and miniature roentgenography. Journal of Bone and Joint Surgery, 55, 1276-1293.

Hamilton, A. A. (1918). A study of spastic anemia in the hand of stonecutters. Bulletin of the US Bureau of Labor Statistics, No. 236, US Department of Labor Series, 53, 114-123.

Horváth, F., Kákosy, T., and Villányi, G. (1969). Structural changes of the carpal bones in motor saw workers. Magyar Radiologia, 21, 257-266. (In Hungarian; English summary).

Hunter, D. (1964). The Diseases of Occupations, 3rd edition, p. 850. English Universities Press, London.

Karjalainen, P. (1973). A method for determination of the mineral content and mineral density of the distal radius using gamma ray attenuation. Annals of Clinical Research, 5, 231-237.

Kumlin, T. (1970). Densitometric studies on metacarpal bones of workers exposed to vibrating tools. WorkEnvironment-Health, 7, 57-58.

(1973). The vibration disease-traumatic vasospastic disease (TVD) or syndrome (TVS). Duodecim, 89, 11-18. (In Finnish; English summary).

- Wiikeri, M., and Sumari, P. (1973). Radiological changes in carpal and metacarpal bones and phalanges caused by chain saw vibration. British Journal of Industrial Medicine, 30, 71-73.

Kylin, B. and Lidström, I. M. (1970). Vibration disorders in forestry workers. National Institute of Occupational Health, Stockholm, Sweden.

de Larrard, J. and Saldarkhan, P. (1970). Maladie de Kienboeck très invalidante chez un bûcheron landais. Archives des Maladies Professionelles, de Médecine, du Travail et de Sécurite Sociale, 31, 330. 
Lassen, N. A., Lindbjerg, I. F., and Munck, O. (1964). Measurement of blood flow through skeletal muscle by intramuscular injection of Xe-133. Lancet, 1, 686.

McLaren, J. W. (1937). Disability of workers using pneumatic drills. Lancet, 2, 1296.

Meiss, W. C. (1933). Gelenksveränderungen durch die Benutzung von durch Pressluft getriebenen Werkzeugen. Monatsschrift für Unfallheilkunde und Invalidenwesen, 40, 453-462.

Saville, P. D. and Whyte, M. P. (1969). Muscle and bone hypertrophy. Positive effect of running exercise in the rat. Clinical Orthopaedics, no. 65, 81-88.

Shimmins, J., Smith, D. A., Aitken, M., Anderson, J. B., and Gillespie, F. C. (1972). The accuracy and repro- ducibility of bone mineral measurements 'in vivo': (b) methods using sealed isotope sources. Clinical Radiology, 23, 47-51.

Vainio, K. (1950). Om vibrationssyndrom, särskilt hos maskinborrare. Nordisk Hygienisk Tidskrift, 31, 249-267.

Wilson, R. H., McCormick, W. E., Tatum, C. F., and Creech, J. L. (1967). Occupational acroosteolysis. Journal of the American Medical Association, 201, 577 581.

Received for publication 18 March 1974.

Accepted for publication 6 July 1974 . 